\title{
NBSIR 73-104
}

\section{A Non-Contacting Length Comparator With 10 Nanometer Precision}
A. W. Hartman
F. W. Rosberry
J. Arol Simpson

Institute for Basic Standards National Bureau of Standards

Washington, D. C. 20234

February 9, 1973

Final Report

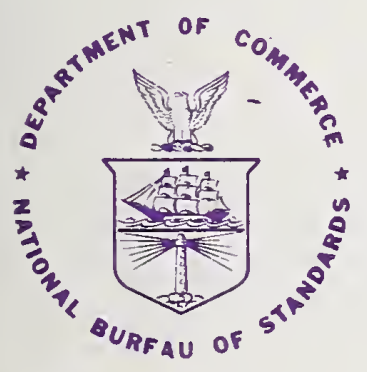

U. S. DEPARTMENT OF COMMERCE

NATIONAL BUREAU OF STANDARDS 

NBSIR 73-104

\section{A NON-CONTACTING LENGTH COMPARATOR WITH 10 NANOMETER PRECISION}
A. W. Hartman
F. W. Rosberry
J. Arol Simpson

Institute for Basic Standards

National Bureau of Standards

Washington, D. C. 20234

February 9, 1973

This report is to be superseded by a future publication which will receive general distribution and should be cited as a reference. Please consult the NBS Office of Technical Information and Publiccations to obtain the proper citation. 

CONTENTS

Page

Abstract . . . . . . . . . . . . . . . . . . 1

Introduction . . . . . . . . . . . . . . . . . . . . 1

Principle of Operation . . . . . . . . . . . . . . . 2

Linear Range . . . . . . . . . . . . . . . . . 5

Measurements of Displacement and Lengths with the Prototype

Simon Comparator . . . . . . . . . . . . . . 6

Measurement of Transparent Objects . . . . . . . . . . 7

Measurement of Objects with Diffuse Surfaces . . . . . . . 8

Sensor Signal Levels . . . . . . . . . . . . . . 8

Noise Sources . . . . . . . . . . . . . . . . 10

Measurement Error Sources . . . . . . . . . . . . . 12

Thermal Errors . . . . . . . . . . . . . . . . . 12

Optical Errors . . . . . . . . . . . . . . . . 13

Transfer Curve Errors . . . . . . . . . . . . . . 14

Electrical Factors . . . . . . . . . . . . . . 15

Outlook . . . . . . . . . . . . . . . . . . 16

References . . . . . . . . . . . . . . . . 16

Illustrations (Figures 1 - 16) . . . . . . . . . $17-32$ 

Fig. 1 Simon probe radiometry

Fig. 2 Simon probe layout

Fig. 3 Internal illumination system

Fig. 4 Sensor output vs. object displacement ("transfer curve") 20

Fig. 5 Linear range vs. sensor spacing

Fig. 6 Improving probe linearity by sensor spacing adjustment

Fig. 7 Transfer curve and local slope

Fig. 8 Prototype Simon comparator

Fig. 9 Response to a transparent object

Fig. 10 Response to specular and diffuse reflecting surfaces

Fig. 11 Sensor response to specular and diffuse reflecting surfaces 27

Fig. 12 Preamplifier diagram

Fig. 13 Probe noise vs. integration time

Fig. 14 Probe noise vs. signal strength

Fig. 15 Probe offset error

Fig. 16 Specimen rotations due to repositioning 

A Non-Contacting Length Comparator with 10 Nanometer Precision

by

\author{
A. W. Hartman, F. W. Rosberry and J. Arol Simpson \\ National Bureau of Standards \\ Washington, D.C. 20234
}

Abstract

A non-contacting length comparator utilizing two specially designed photo-electric microscopes has been constructed. Performance tests of this comparator, using lapped and polished steel surfaces demonstrate a resolution of $\sim 1$ nanometer, a precision of $\sim 10$ nanometers, and a linear range in excess of 50 micrometers.

Introduction

J. Simon ${ }^{(1)}$ has described the use of energy sensing in two planes, on either side of the microscope image plane, as a detector of position along the optical axis on the sub-micrometer scale. J.A. Simpson (2) has shown that this scheme should produce sensitivities below 10 nanometers when comparing lengths, and using a common research microscope as a basis.

To test these predictions, a prototype length comparator was constructed, and tested against high quality gage blocks. Also, the first order radiometric theory of reference 2 has been expanded to include the concept of linear range, applicability of diffuse as well as specular 
reflecting test surfaces, estimates of signal-to-noise ratios and error sources .

At present, the resolution is better than 1 nanometer. The precision, defined as repeatability of response to the same stimulus repeated after a period of time, is about 10 nanometers. There are indications that the ultimate precision may lie in the 1 nanometer class.

\section{Principle of Operation}

The basic simon probe is shown in figure 1. A microscope with internal illumination (not shown) illuminates an object which is placed such that two out-of-focus sensors 1 and 2 produce equal output and hence zero difference signal. A variation $\Delta q$ in the object distance $q$ will bring one sensor toward focus. The sensors are a distance $\Delta p$ away from the microscopic image plane, which itself is a distance $p$ away from the microscope objective. The sensors have an area $A_{0}$, the sensor illuminating beam has a cross section $A$ at the sensor plane. The microscope transmits radiation with flux $F_{0}$. The sensors intercept flux $F$ which is a fraction $S$ of $F_{0^{*}}$. This $S$ can be equated with the sensed signal from each detector.

When the object is displaced by a small amount $d(\Delta q)$ from the equilibrium position, S varies by a small amount dS, and the system sensitivity to axial displacements can be expressed as

$$
\frac{d S}{d(\Delta q)}
$$


provided the sensors are able to sense dS in the first place.

The expression for

$$
\frac{d S}{d(\Delta q)}
$$

has been derived in reference 2 for the case of a vanishing small illuminated area of the object surface and a moderately small numerical aperture. This derivation is included below, to illustrate the relative importance of the variables involved.

We have the following equations:

$$
S=\frac{F}{F_{0}}=\frac{A_{0}}{A} \cong \frac{A_{0}}{\pi\left(\theta_{\Delta p}\right)^{2}} \text { for } \theta<1
$$

Lens magnification

$$
\begin{aligned}
& M= \frac{\tan \phi}{\tan \theta} \cong \frac{\phi}{\theta} \text { for } \theta \text { and } \phi \text { small } \\
& M^{2} \cong \frac{\Delta p}{\Delta q} \quad \text { for } M \gg 1 \text { and } \Delta p<p
\end{aligned}
$$

Therefore,

$$
S \cong \frac{A_{0}}{\pi(\theta \Delta p)^{2}}=\frac{A_{0}}{\pi M^{2} \phi^{2}(\Delta q)^{2}}
$$

and hence

$$
\Delta q=\frac{1}{M \phi} \sqrt{\frac{A_{0} F_{0}}{\pi F}}
$$

For a given operational value of $\mathrm{S}$, its variation with $\Delta \mathrm{q}$ is: 


$$
\frac{\partial S}{\partial(\Delta q)}=\frac{-2 A_{0}}{\pi M^{2} \phi^{2}(\Delta q)^{3}}=-2 M \phi \sqrt{\frac{\pi F^{3}}{A_{0} F_{0}^{3}}} .
$$

For the two sensors combined, we have then

$$
\frac{\partial S}{\partial(\Delta q)}=-4 M \phi \sqrt{\frac{\pi F^{3}}{A_{0} F_{0}^{3}}} .
$$

For the prototype, where

$$
\left.\begin{array}{l}
A_{0}=1 \times 10^{-6} \mathrm{~m}^{2} \\
A=4 \times 10^{-6} \mathrm{~m}^{2}
\end{array}\right\} \quad \therefore \frac{F}{F_{0}}=S=\frac{1}{4}
$$

the resulting values are:

$$
\begin{aligned}
\frac{\partial S}{\partial(\Delta q)} & =-4 \times 20 \times 0.50 \sqrt{\frac{\pi \times \frac{1}{64}}{1 \times 10^{-6}}}=-4000 \sqrt{\frac{100 \pi}{64}}=-8880 \mathrm{~m}^{-1} \\
& =-0.0089 / \text { micrometer }
\end{aligned}
$$

S itself is 0.25 , hence

$$
\frac{\frac{\partial S}{\partial(\Delta q)}}{S}=\frac{-0.0089}{0.25} \times 100 \% / \text { micrometer }=-0.0035 \% \text { per nanometer } \text {. }
$$

This means that if the sensor system is such that equality of sensor 
illumination can be sensed to a precision of $1: 30,000$, axial displacements can be measured with a precision of 1 nanometer. The observed values are typically:

individual sensor output when at equilibrium: 0.6 volt (after ampl.) detectable change in sensor output: 0.1 millivolts (after ampl.) detectable object displacements: 0.2 microinch, or 5 nanometers. These values therefore support the above analysis.

In order to illuminate both sensors, the arrangement of figure 1 is actually constructed as in figure 2, using appropriate beam splitters. The illumination system is of the Kohler type as in figure 3. This provides pencils of parallel light landing on the specimen in all directions, up to the limit set by the numerical aperture of the microscope objective.

\section{Linear Range}

The Simon probe normally operates in a null-mode: the probe is displaced by a measured amount in order to bring the displaced specimen back in focus. An alternate way is to leave the Simon probe fixed, and use the unbalanced sensor output to derive the object displacement.

For each sensor, the output vs displacement is a bell-shaped curve as in figure 4 with a maximum when the sensor is in focus. If the sensors are connected such as to produce output difference, the two focus curves combine to an S-like curve. When the sensor distance "a" is properly selected, the S-shaped "transfer curve" shows a fairly large 
Inear range of apprectable length (of the order 5000 resolution elements).

If the sensor distance "a" is selected improperly, the range shortens and non-linearity results, as shown in figures 5 and 6 . A transfer curve which appears on inspection to be linear such as in figure 7 , can actually still contain nonlinearities of several percent. The graph can not show these variations in the slope of the transfer curve, but they can be calculated from the sensor data.

Measurements of Displacements and Lengths with the Prototype Simon Comparator

The measurement of displacement involves one Simon probe, looking at one face of the object being displaced along the optical axis. For determination of object length, two Simon probes are needed, on a common optical axis and looking at opposite faces of the object.

The probes are connected such as to produce the difference between the two probe outputs, and they have been adjusted such as to have equal transfer curve slope at zero-output conditions. This feature insures that small displacements of the object along the optical axis are not read as changes in object length.

The length measurement is carried out as a comparison of the unknown with that of a known, nearly equal, length. The comparison can span a range twice as large as the dynamic range of a single Simon probe, or typically 100 micrometers. The prototype Simon Probe Comparator is constructed 
such as to allow rapid comparison of gage blocks, and looks much like a microscope with vertical optical axis (figure 8 ).

The gage block under test is positioned, against stops, on a horizontal stage. One Simon probe is mounted under this stage, looking at the bottom surface of the block. Another Simon probe is positioned over the block, connected to a vertically mounted differential micrometer slide. This slide has a range of 0.010 inch and resolution $1 \times 10^{-6}$ inch.

Measurement of Transparent Objects

Displacement and length measurements of transparent objects, such as gage blocks made from low-expansion glass, are carried out in the same manner as for opaque objects. In both cases, the surface will be polished, and exhibit specular reflection. The reflection coefficient of the transparent object will in general be smaller, with a corresponding loss in signal strength and measurement precision.

A complication arises if the thickness of the transparent object is comparable to or smaller than the base width of the focus curve of each Simon probe sensor. The focus curve of each sensor will then exhibit two peaks instead of one, corresponding to it picking up the reflection of top and bottom surface. If these peaks are too close together, the transfer curve of the Simon probe becomes distorted, as in flgure 9. This can be avoided by keeping the thickness an order of magnitude larger than the dynamic range of the Simon probe, or typically larger than 500 micrometers. 
Measurement of Objects with Diffuse Surfaces

If the object has a diffuse surface, with structure details small relative to the diameter of the illuminated area, the measurement of displacement and length can be carried out in the same was as for specular surfaces, although a question will arise as to what surface plane the Simon probe actually measures. The precision with which the diffuse surface can be located and thereby its displacement measured, is less than for polished metal surfaces for the following reasons:

(a) the object scatters a large part of the illumination outside the acceptance angle of the microscope objective.

(b) The illuminated area as sensed by the two Simon probe sensors is always located right at the object surface, while this plane displaces at twice the rate when an object with specular surface is displaced. Consequently, the focus curve of each sensor is twice as broad for a diffusing surface as for a specular surface. This will result in a transfer curve of the Simon probe which has its slope reduced by one-half.

The above behavior will be somewhat modified by the fact that the surface brightness of the diffusing surface does not remain constant with displacement. The broadening effect of the focus curve is shown in figure 10, while the reduction in the transfer curve slope and in signal levels is shøwn in figure 11.

Sensor Signal Levels

The internal illumination system collects energy from the source 
within a cone of $3 \times 10^{-4}$ steradian; this low value is due to the large optical demagnification. The two-way transmission, including $90 \%$ specular reflection from the specimen, is estimated at $1.4 \%$. An additional diffuser for improved uniformity lowers this value to $0.95 \%$. The light source is a $45 \mathrm{~W}$ quartz-iodine lamp with estimated blackbody temperature $3000 \mathrm{~K}$ and emissivity 0.5 .

When a sensor is in focus, it senses a calculated $2.7 \times 10^{-7}$ Watt. When in balance with the other sensor, the sensed energy is 3 to 4 times less (see figure 11 ) or $0.7 \times 10^{-7} \mathrm{~W}$. This estimate can be checked as follows: observed output under balanced conditions is typically $0.6 \mathrm{~V}$ at the meter (figure 8 ), hence $0.1 \mathrm{~V}$ at the preamplifier, the detector current is then $1 \times 10^{-8} \mathrm{~A}$ and its irradiance $1 \times 10^{-7} \mathrm{~W}$, using a broadband responsivity of $0.1 \mathrm{~A} / \mathrm{W}$.

The irradiance levels and spectral distribution suggest as sensor candidate a photovoltaic silicon diode, such as the HP-4207. This particular diode has been used in the prototype Simon length comparator.

One can introduce thermal protection of the mechanical structure by long-wavelength blocking of the incoming radiation. This changes the broad-band responsivity, as shown below. It has not been used as yet.

\begin{tabular}{|c|c|c|}
\hline$\frac{\text { Spectral Bank }}{n \mathrm{~m}}$ & $\frac{\text { Heat Blocked }}{\%}$ & $\frac{\text { Broad-band Responsivity }}{A / W}$ \\
\hline 400 - inf. & zero & 0.094 \\
\hline $400-1100$ & 65 & 0.27 \\
\hline $400-900$ & 79 & 0.21 \\
\hline 632.8 (he: $\mathrm{Ne}$ ) & near $100 \%$ & 0.45 \\
\hline
\end{tabular}




\section{Nolse Sources}

The main noise sources are: shot noise, Johnson noise and circuit noise. The circuitry consists of: (1) a preamplifier for each sensor with gain $6.5 \mathrm{x}$ and input impedance $10 \mathrm{M} \Omega$ (2) a signal subtraction unit, and (3) an integrating voltmeter with integration time $0.1,1$, and 10 seconds. A diagram of the circuitry is shown in figure 12 .

With 0.1 second integration time, the estimated noise figures are found as follows: The detector current is $14 \mathrm{nA}$, the shot noise is $1.5 \times 10^{-13} \mathrm{~A} \mathrm{rms}$, or $1.5 \times 10^{-6} \mathrm{~V}$ rms at the preamplifier input or $10 \times 10^{-6} \mathrm{~V}$ at the meter. The Johnson noise for $10 \mathrm{M} \Omega$ and 0.1 second is $1.3 \times 10^{-6} \mathrm{~V}$ rms at the meter. With 1 second integration time, the rms noise figures go up about 3 times while their relative values (compared to the signal) decrease by a factor 3). The latter change will show on the voltmeter, because the displayed signal is by internal means kept independent of the integration time.

The total system noise can be estimated by plotting repeated meas urements under controlled conditions, from visual inspection one derives "maximum" fluctuation amplitudes which can be considered $3 \sigma$ fluctuations. The following variables were used:

Signal: zero, half-value, full-value

int. time: $0.1,1,10$ seconds

Simon units used: one, two

The results are plotted in figures 13 and 14, from which one can 
read the following $3 \sigma$ amplitudes:

Conditions

0.1 sec int. time
$3 \sigma$ Amplitude of total system noise

1 sec int. time

Top Unit

$\begin{array}{lll}\text { zero signal } & 0.1 \times 10^{-4} \mathrm{~V} & 0.04 \times 10^{-4} \mathrm{~V} \\ \text { half signal } & 0.3 & 0.05 \\ \text { full signal } & 0.5 & 0.05\end{array}$

Both Units

$\begin{array}{lcc}\text { zero signal } & 0.1 & 0.06 \\ \text { half signal } & 0.7 & 0.6 \\ \text { full signal } & 1.5 & 1.2\end{array}$

The following tentative conclusions can be drawn:

(1) Dark noise is $1 \times 10^{-5} \mathrm{~V}$ rms at $0.1 \mathrm{sec}$ and $0.5 \times 10^{-5} \mathrm{~V} \mathrm{rms}$ at 1 second. These values compare with anticipated shot noise and Johnson noise levels.

(2) For illuminated sensors, a large noise value exists which is about proportional to signal level. This behavior is not clear under low-noise conditions (one probe, 1 second int. time). This noise contribution is likely due to circuitry.

(3) Two-unit operation is about 2 to 3 times noisier than one-unit operation.

(4) At higher noise levels, noise reduction by longer integration 
time is less effective than at low noise levels.

\section{Measurement Error Sources}

The error sources for an operating single or double simon probe are of a thermal, optical, mechanical and electrical nature. It is easy to lose an order of magnitude in accuracy if the design and the operation of the Simon probes is not very carefully controlled.

At present, the Simon probe has demonstrated in prototype operation a sensitivity of about 3 nanometers or 0.1 microinch. The precision has not been fully determined; preliminary estimates are in the 10 nanometer class.

In the following sections, an outline is given of potential and identified error sources.

\section{Thermal Errors}

Thermal errors result from dimensional changes in the specimen or instrument caused by ambient heat sources, such as a lamp, the human body, etc. The length of the measurement cavity is a function of the structural assembly temperature, and it is a very sensitive function of certain temperature gradients within this assembly.

The approximate magnitude of various thermal errors are:

(a) A temperature change of $0.01^{\circ} \mathrm{C}$ causes in a steel specimen (gage block) of $25 \mathrm{~mm}$ length an error of $3 \mathrm{~nm}$.

(b) The same temperature change, in a steel structure that keeps the two probes $25 \mathrm{~mm}$ apart, causes the same error $3 \mathrm{~nm}$. Errors a and b 
can be made to cancel in the steady state by material sclection.

(c) The Influence of a temperature gradient can be seen from this example: let the probe holding structure be equivalent to a "C-clamp" of radius $R$, thickness $d$, linear expansion coefficient $\lambda$, and radial temperature difference $\Delta T$. The measurement cavity, assumed small relative to $R$, will change by:

$$
x=\frac{2 \pi \lambda R^{2} \Delta T}{d} .
$$

With

$$
\begin{aligned}
R & =5 \mathrm{~cm} \\
d & =2 \mathrm{~cm} \\
\lambda & =12 \times 10^{-6} \\
\Delta T & =0.01^{\circ} \mathrm{C}
\end{aligned}
$$

we find

$$
\mathrm{x}=90 \mathrm{~nm}
$$

which is an amount far larger than the errors a and b. The prototype design attempted to minimize this effect.

$$
\text { Optical Errors }
$$

These errors are primarily alignment errors.

(1) Misalignment within the probe. The object plane, as defined by balanced sensor output, is not coincident with the object plane ag defined by the location of the illuminated pinhole image. Such a mls alignment causes an offset error: zero sensor output for a speculer reflecting specimen and for a diffuse specimen occur at different 
specimen locations, as shown in figure 15. A typical value for this offset error is 50 microns.

(2) Misalignment between two probes. When the two probes are not colinear, the measurement of the thickness L of a lisghtly tilted specimen develops an error. If the probe offset is $D$ and the tilt is $\alpha$, the error in $L$ is approximately $x_{D}$. In practice, tilt errors of $2-5 \times 10^{-5}$ rad are common. An indication of this is shown in figure 16, for the case of a gage block supported on three small and fixed steel balls.

The prototype instrument has a measured offset $D=0.15 \mathrm{~mm}$. When $\alpha=5 \times 10^{-5}$, the error is $7.5 \mathrm{~nm}$.

(3) Cosine Errors. This error occurs with a tilted specimen between two we11-aligned $(D=0)$ Simon probes. The error is equal to $1 / 2 \alpha^{2} \mathrm{~L}$. When $\mathrm{L}=25 \mathrm{~mm}$ and $\alpha=5 \times 10^{-4}$, the cosine error is $3 \mathrm{~nm}$.

Trans fer Curve Errors

The main features of the transfer curve are:

(1) The zero-crossing point.

(2) The overall slope.

(3) The slope linearity.

The main uses of this curve are:

(1) As a null-indicator (use zero-crossing point only).

(2) As a measurement tool for displacements that are too small to be implemented by standard mechanical means.

The curve features can be altered by the following causes: 
(1) Misalignment within the probe: the zero-point for reflective and for diffusive specimens are not coincident.

(2) Changes in light output of the illuminating system. This changes the curve slope accordingly. The slopes are typically 1000 Volt per inch or $4 \times 10^{-5} \mathrm{~V} / \mathrm{nm}$, while the total span of the linear part of the curve is typically 2 mils $=50$ microns or 2 Volts. If the lamp voltage changes by a factor $10^{-4}$, the output changes by $10^{-3}$ and the sensor signal changes by $\pm 1 \mathrm{mV}$ at the ends of the linear range. Thus, an error can be introduced to an amount $\pm 25 \mathrm{~nm}$ maximum. The power supply for the lamp has therefore to be well-isolated from line and load fluctuations. Likewise, the optical properties (reflection, transmission) of all optical surfaces should be sufficiently stable during the measurement.

\section{Electrical Factors}

The prototype instrument output exhibits short-term fluctuations $(5-20 \mathrm{~nm})$ and long-term $\operatorname{drift}(3-15 \mathrm{~nm} / \mathrm{minute})$. The fluctuations are considerably larger than would be expected from shot noise and Johnson noise. Their source should be sought in the sensor electronics and in the illumination system; this process is in progress at the present time.

There are several ways open to improve the noise figure. One way is to improve the electronics (using lower-noise operational ampliflers, etc.). Another way is to use photomultipliers for the sensors instead of photodiodes. When photomultipliers are used, the shot noise levels will go up somewhat, because the quantum efficiency is 3 to 5 times 
lower. However, the signal levels go up several orders of magnitude, and the relative influence of circuit noise (the main noise factor at present) becomes small. Both approaches are investigated.

\section{Outlook}

The process of comparing lengths using Simon probes is essentially a determination of radiometric balance between two sensors. The obtained precision of this balancing process is not very large at present, as can be seen from this example:

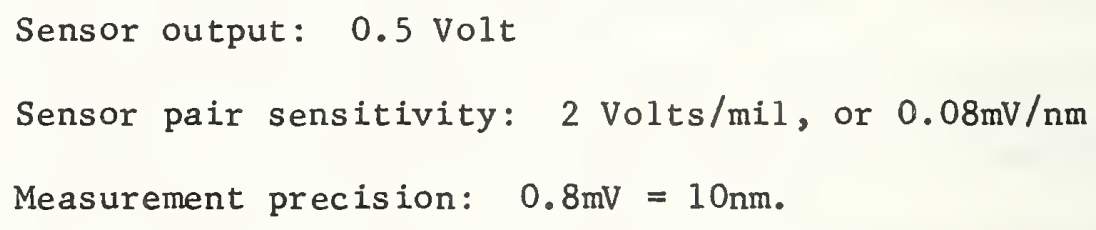

The precision of the radiometric balance determination is $0.8 \mathrm{mV}$ in $0.5 \mathrm{Volt}$, or 1 in 600 , while the sensitivity is 1 in 6000 .

This result does not represent the state-of-the-art; half-shadow techniques using polarization angles can do at least 10 times better; therefore a precision of $1 \mathrm{~nm}$ in Simon probe measurements should be a realizable goal.

References

1. J. Simon, Applied Optics 10, 2337 (1970).

2. J. A. Simpson, Rev. Sci. Instr. 42, 1378 (1971). 


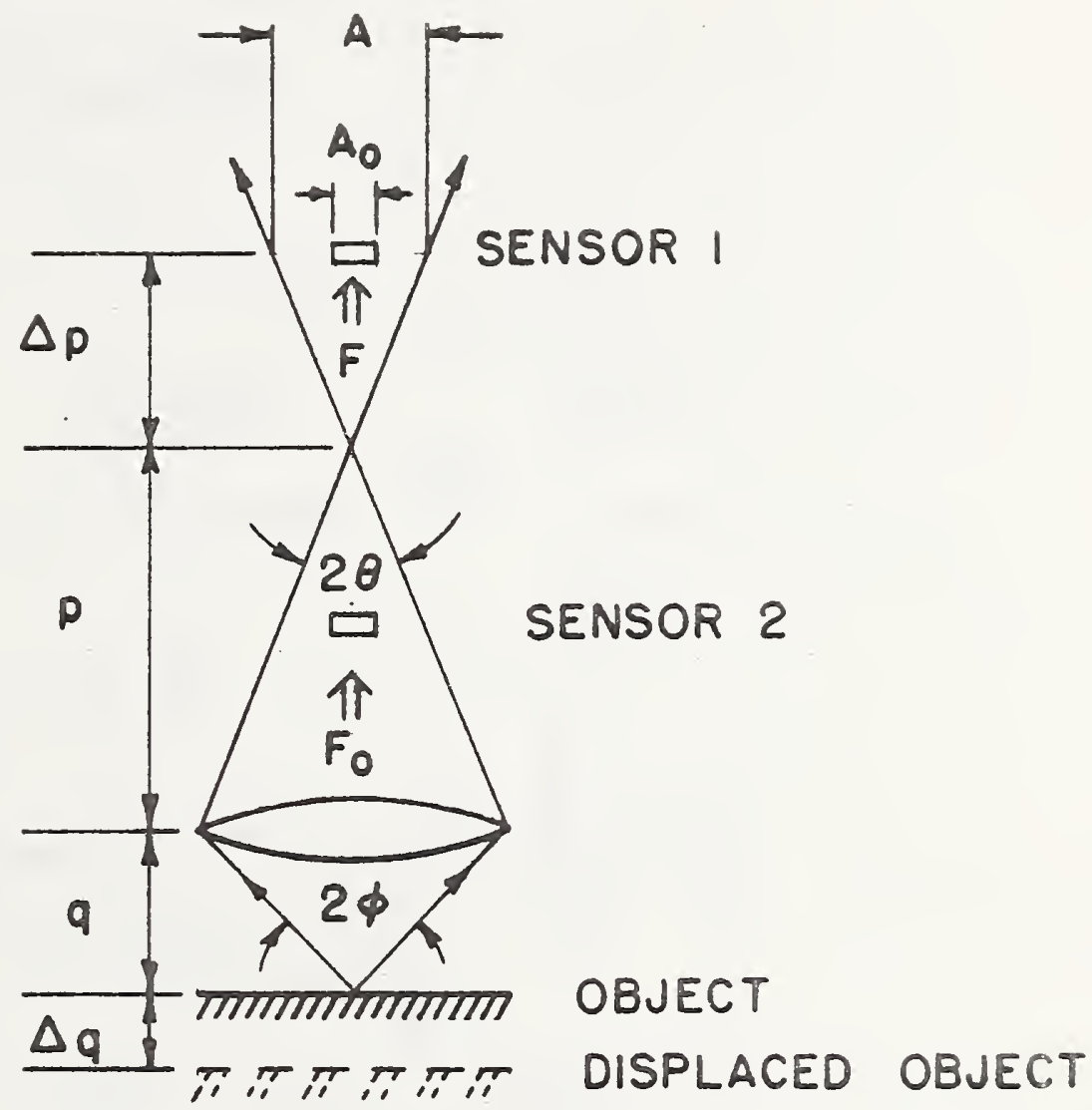

SIMON PROBE RADIOMETRY

FIGURE 1 


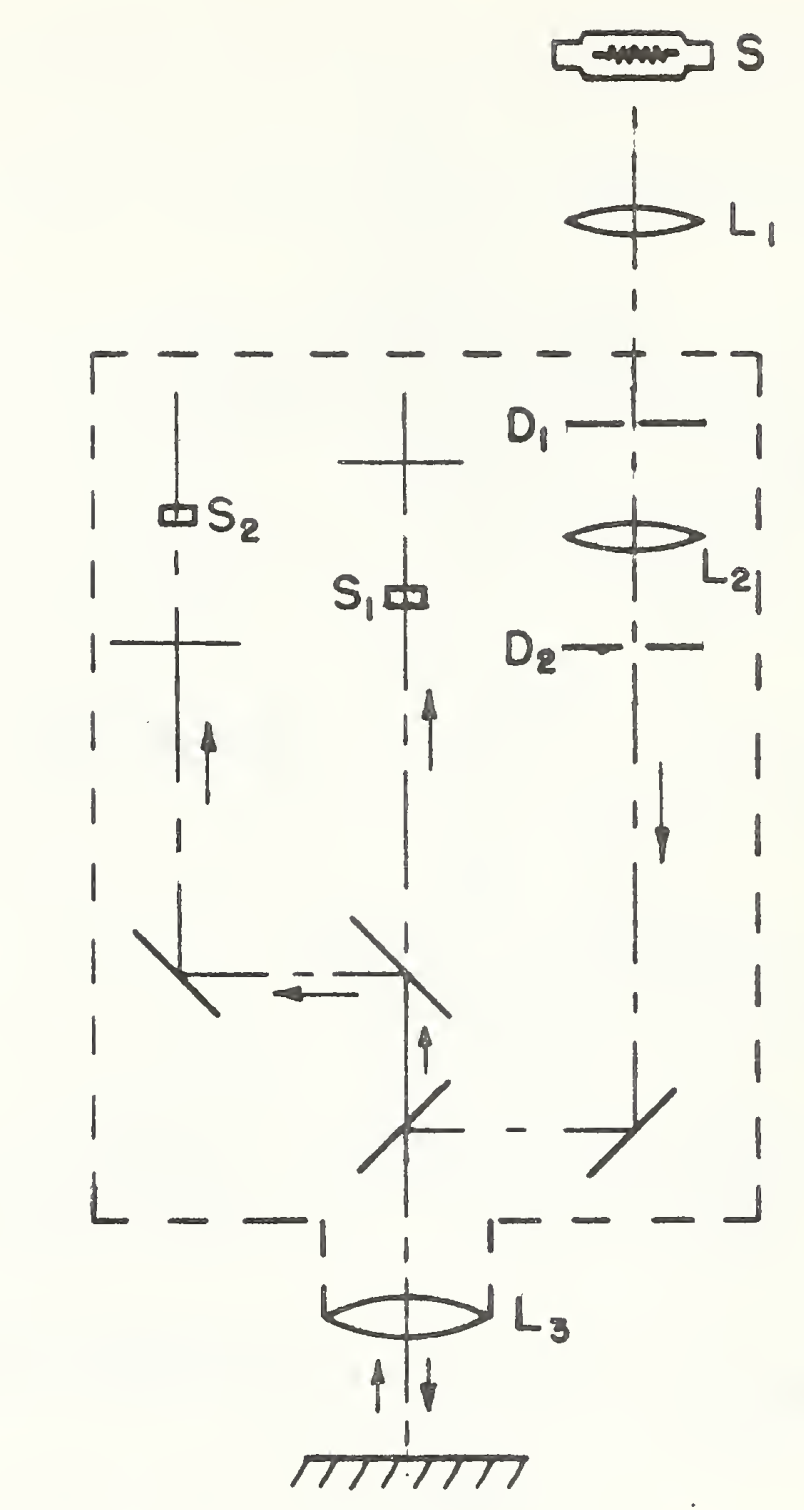

SIMON PROBE LAYOUT

PIGURE 2 


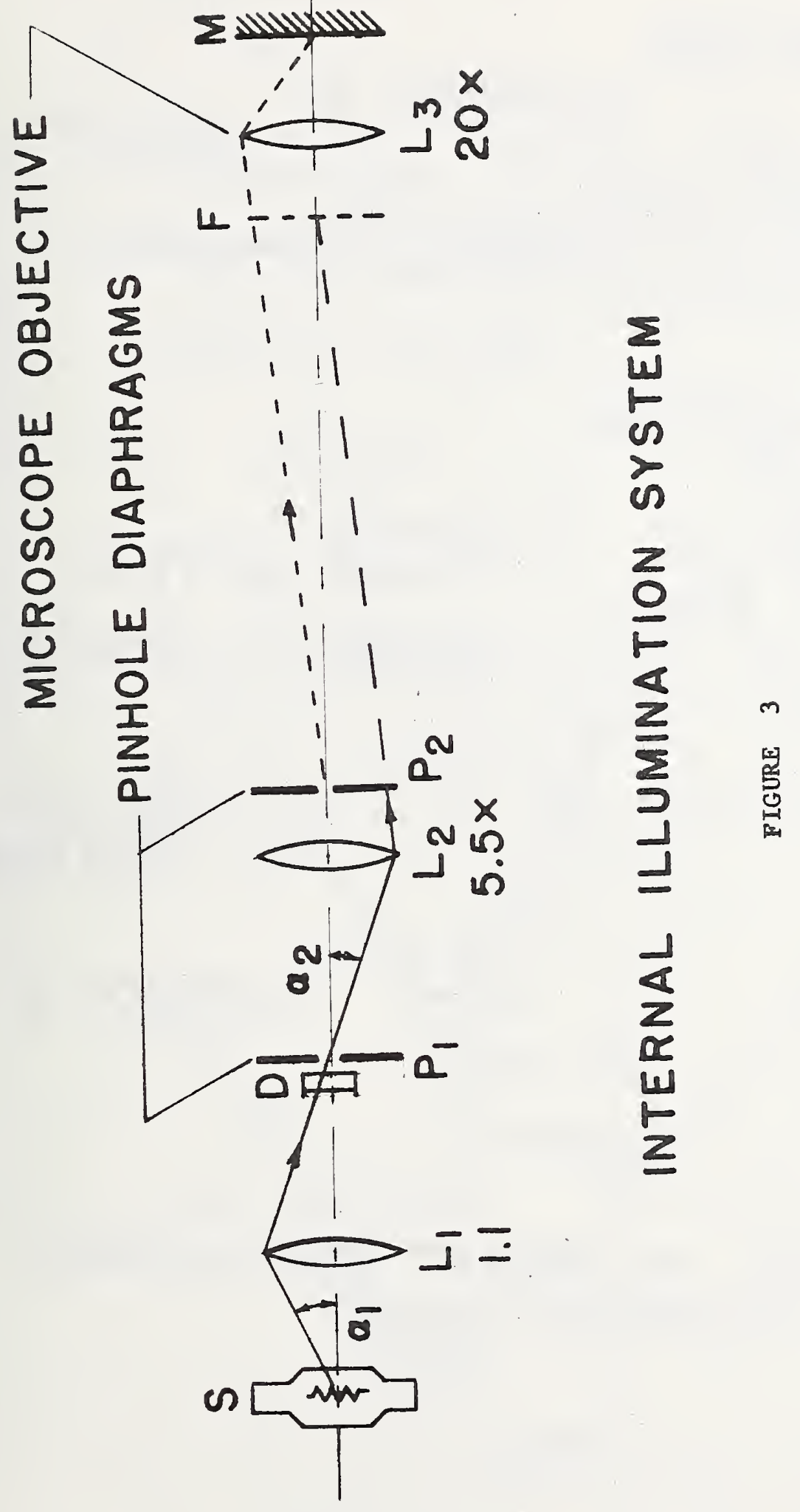




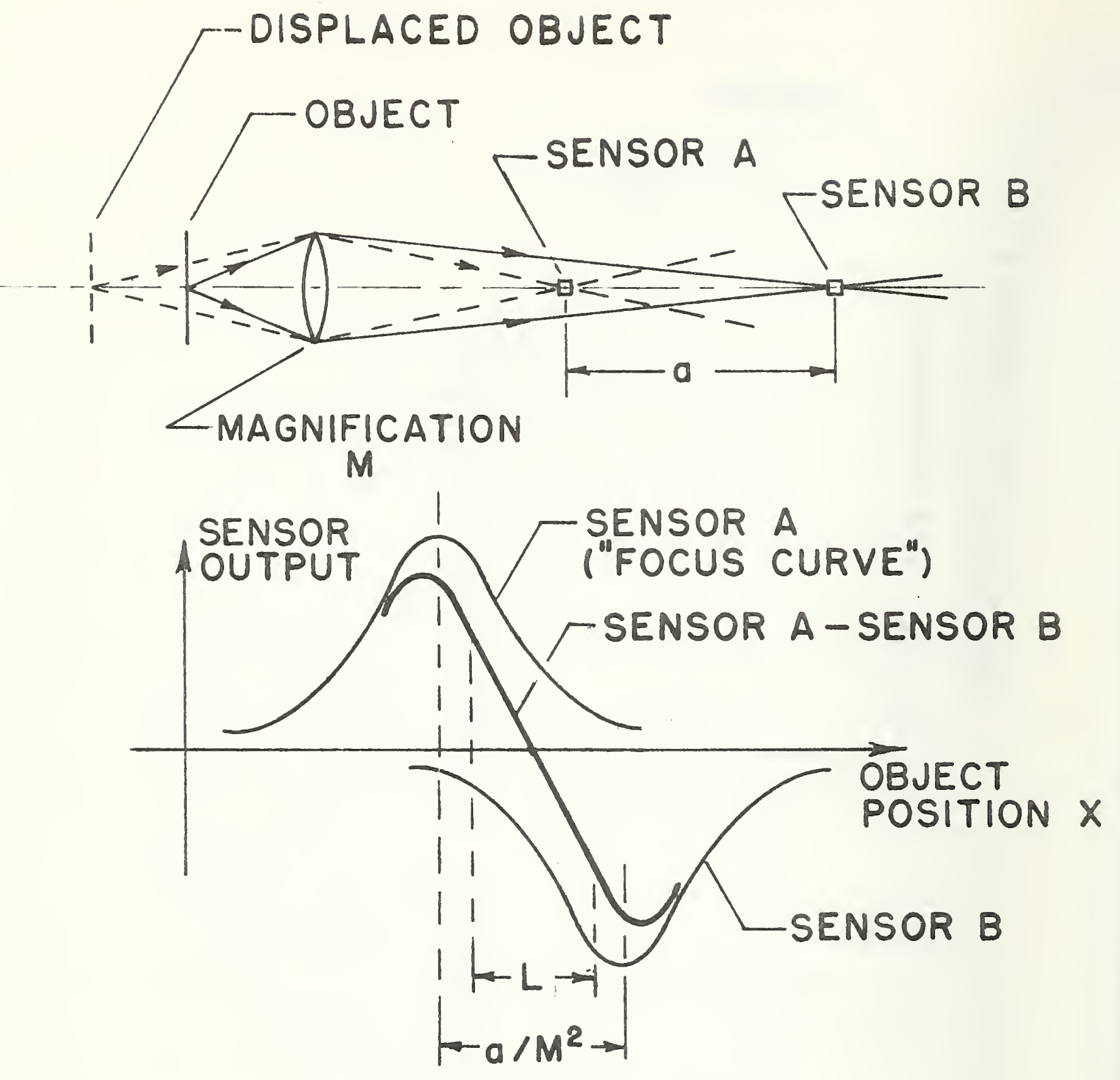

SENSOR OUTPUT VS. OBJECT DISPLACEMENT ("TRANSFER CURVE")

FIGURE 4 

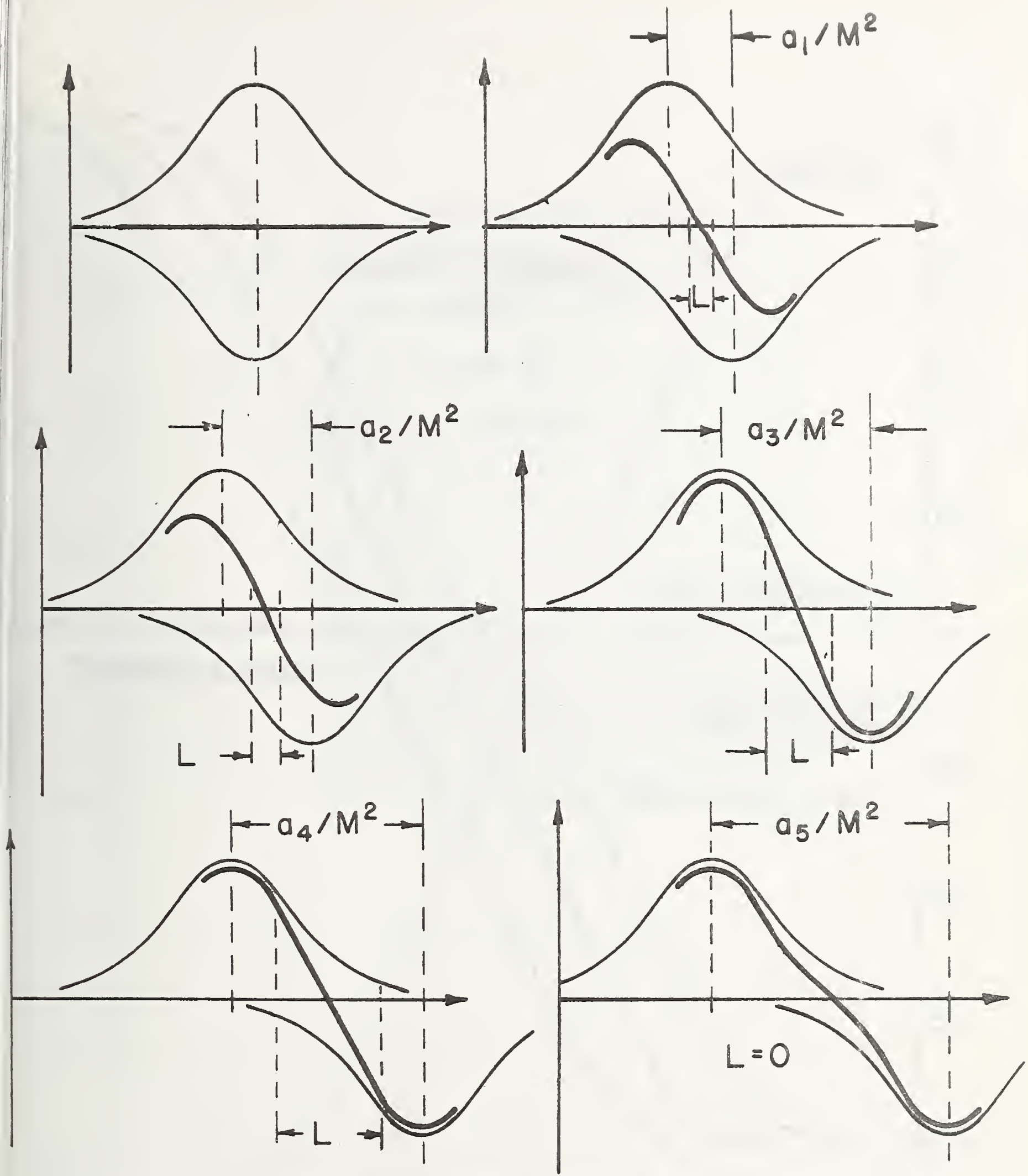

LINEAR RANGE VS. SENSOR SPACING 


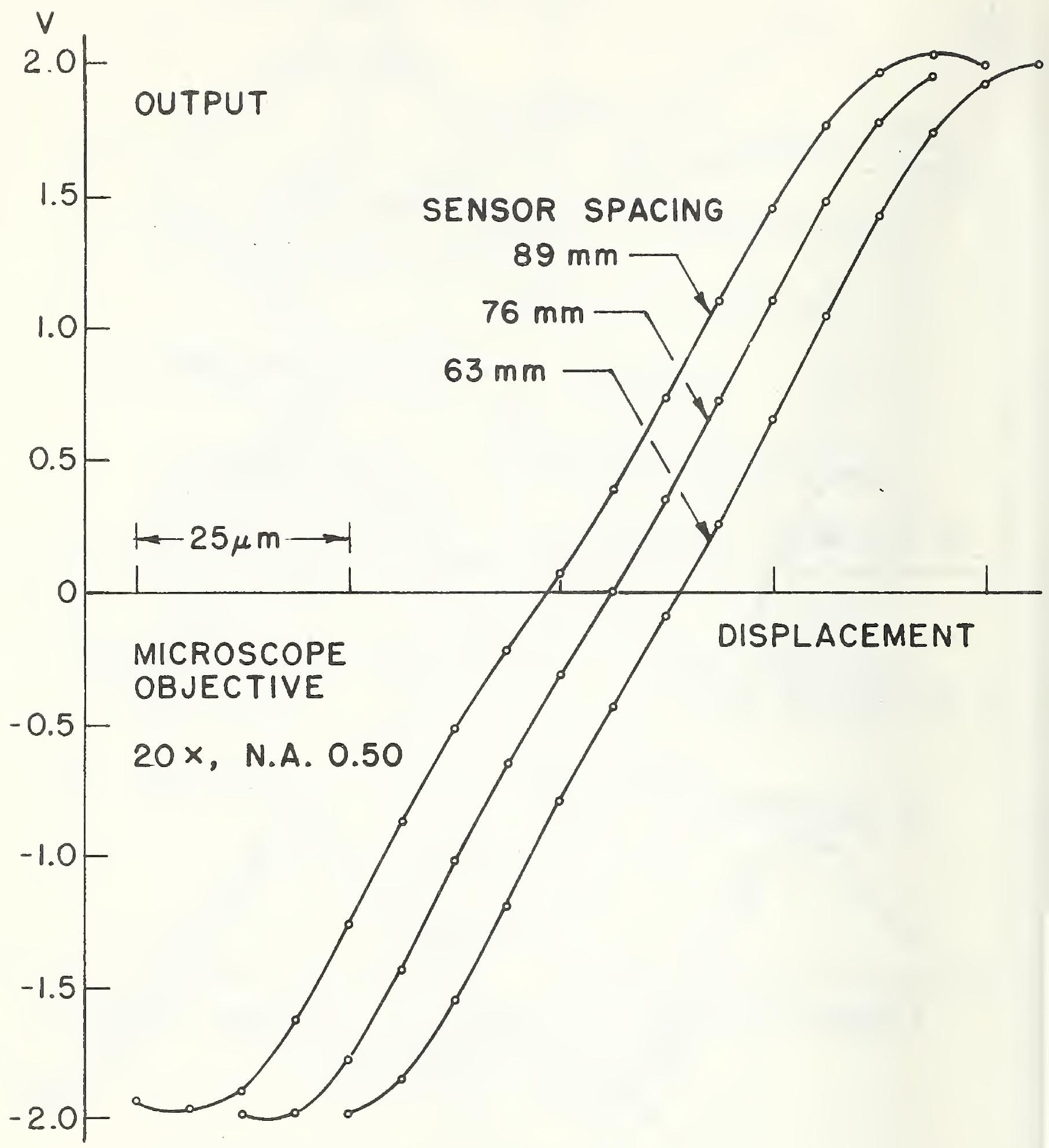

IMPROVING PROBE LINEARITY BY SENSOR SPACING ADJUSTMENT 


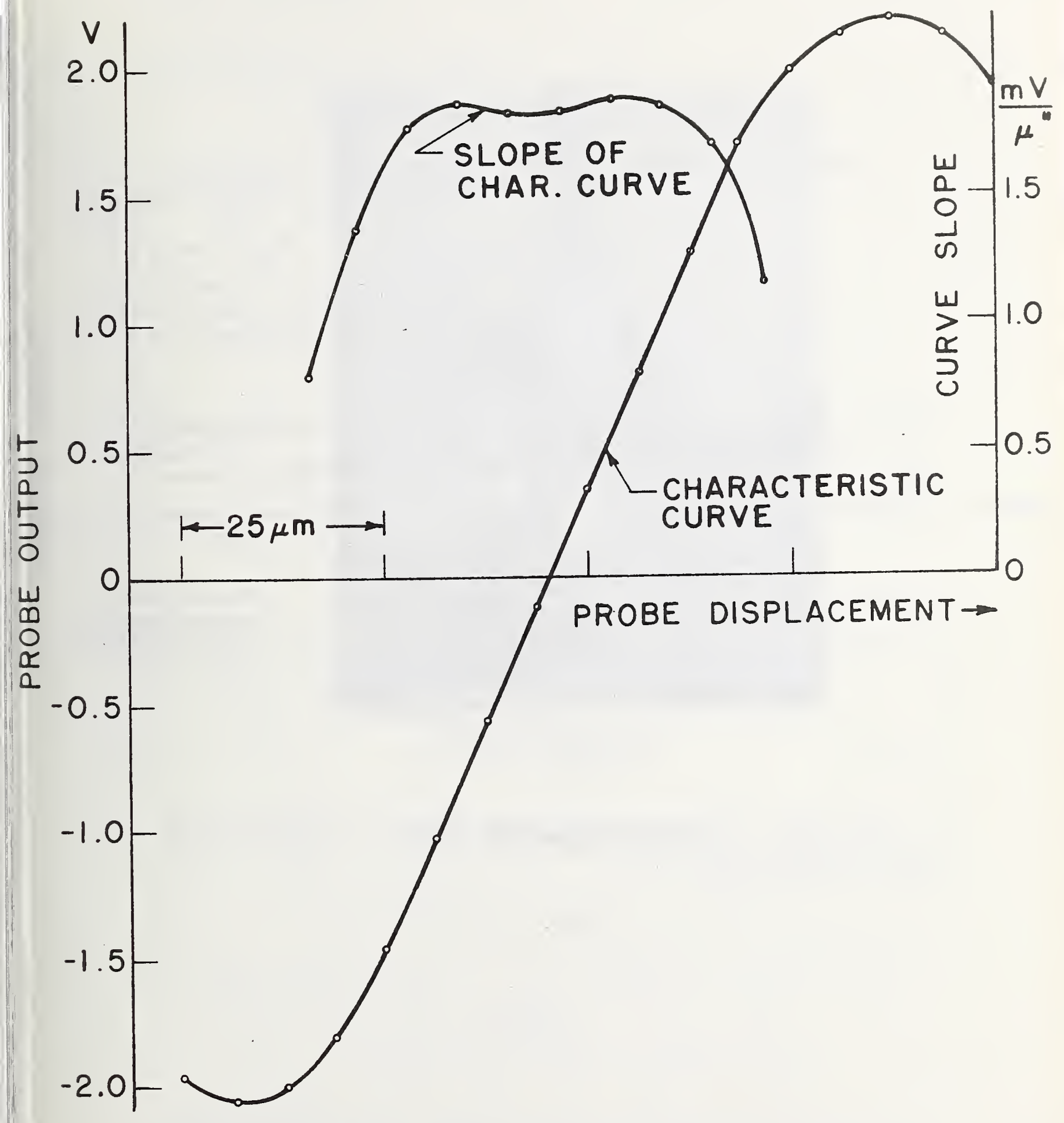

TRANSFER CURVE AND LOCAL SLOPE

FIGURE 7 


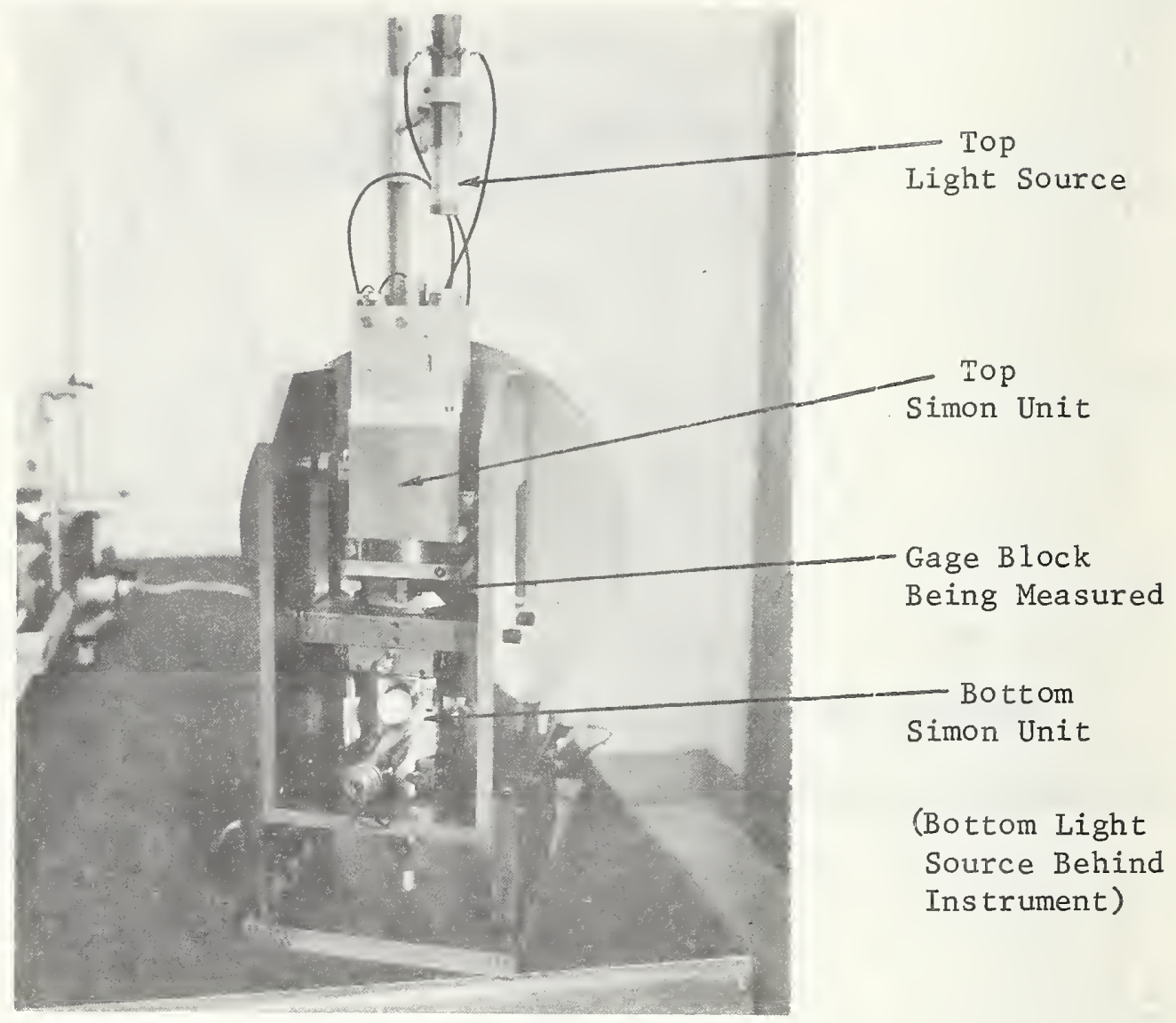

PROTOTYPE SIMON COMPARATOR

FIGURE 8 


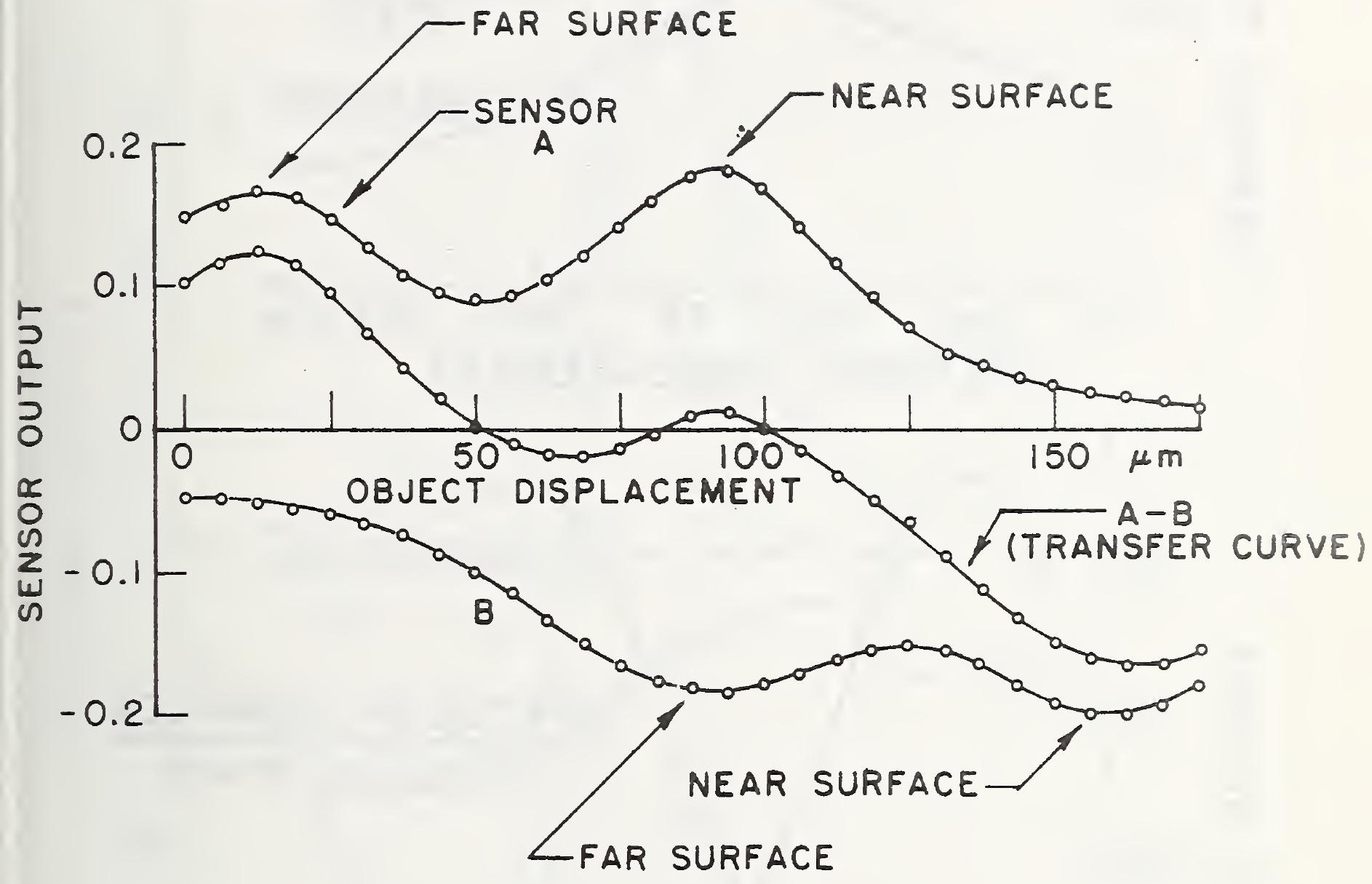

RESPONSE TO A TRANSPARENT OBJECT

(COVER. SLIDE)

FIGURE 9 

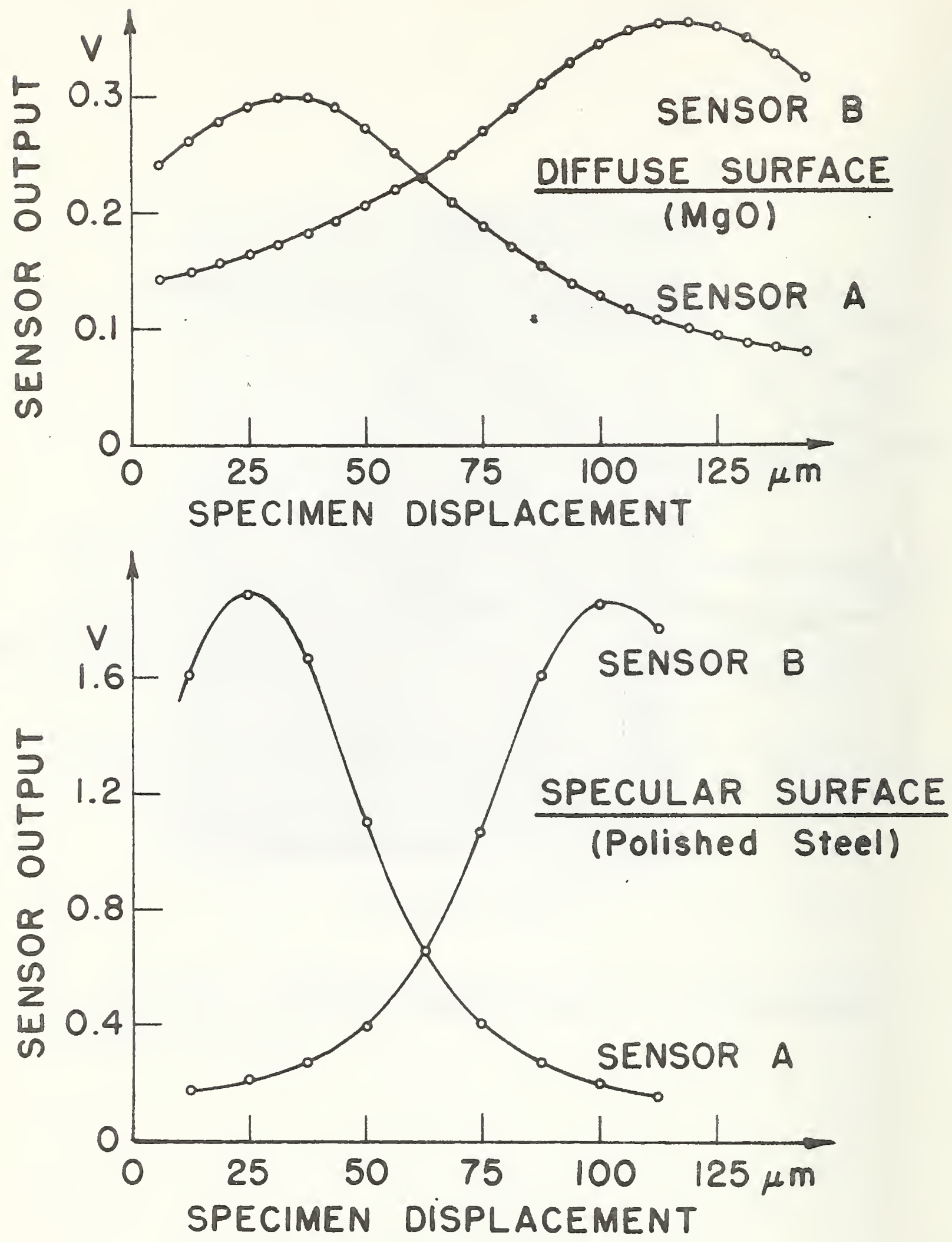

RESPONSE TO SPECULAR AND DIFFUSE REFLECTING SURFACES. 


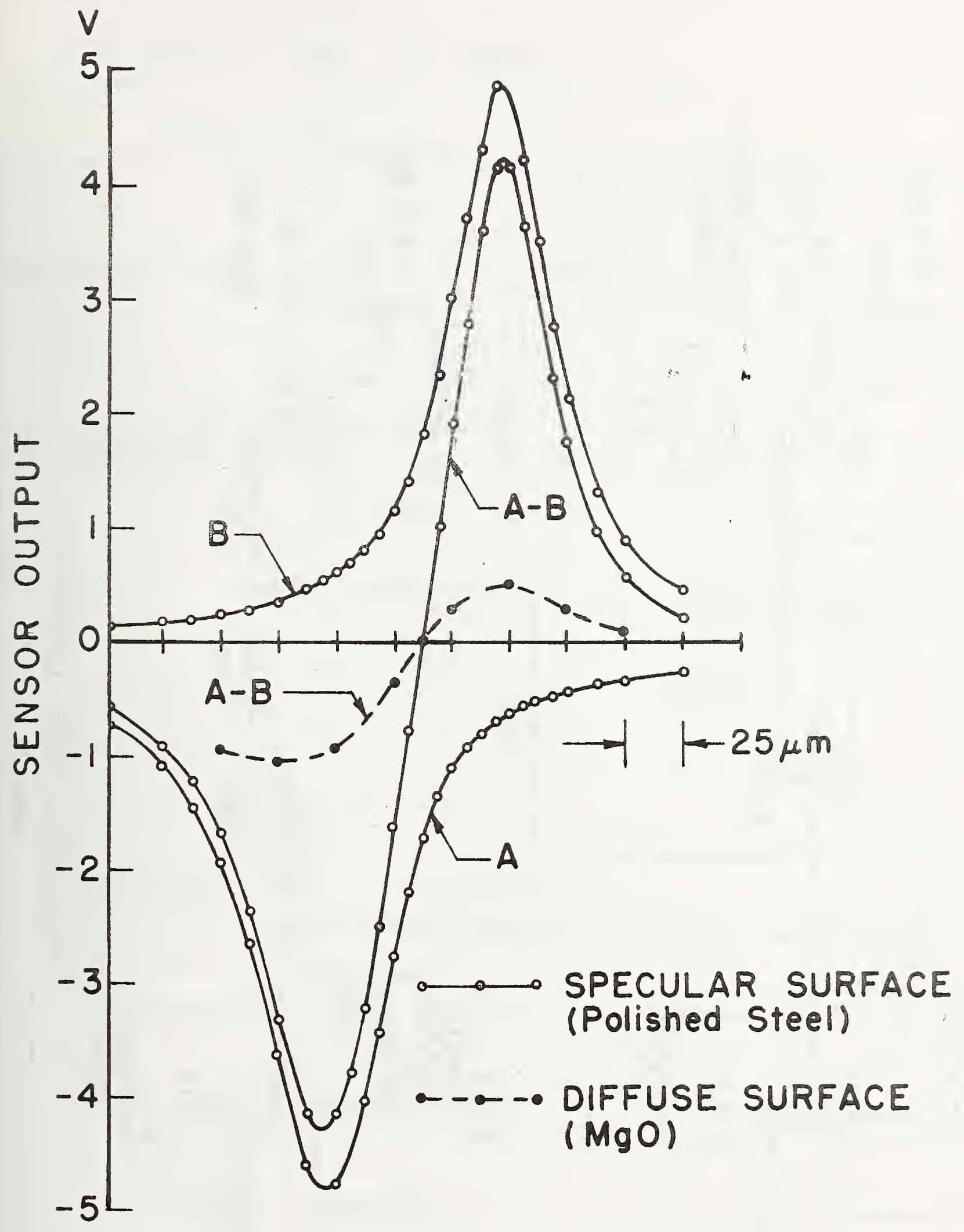

SENSOR RESPONSE TO SPECULAR AND DIFFUSE REFLECTING SURFACES 


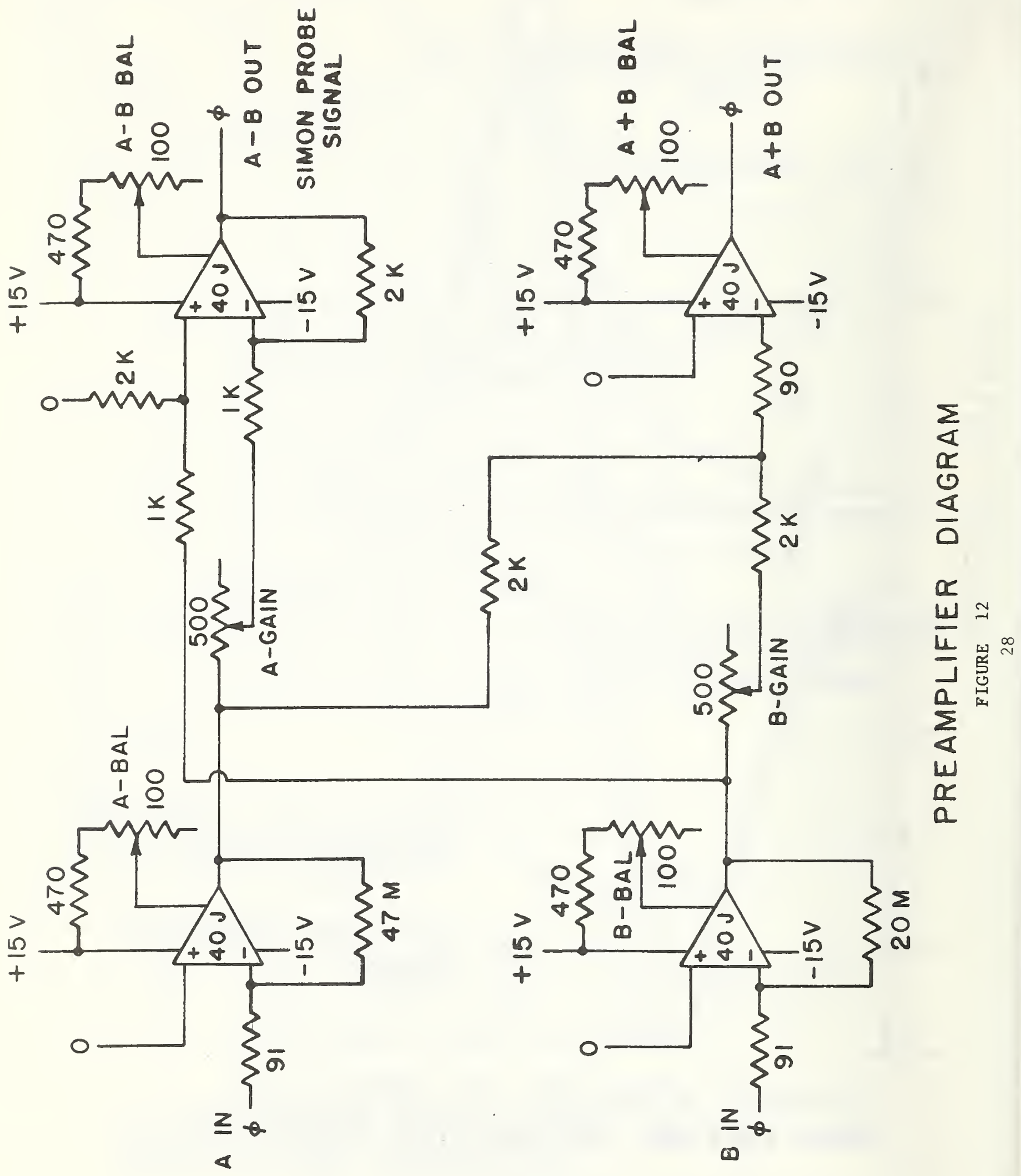




\section{INTEGRATION TIME: OL SARQNO}

1) $. \cdots+\ldots$

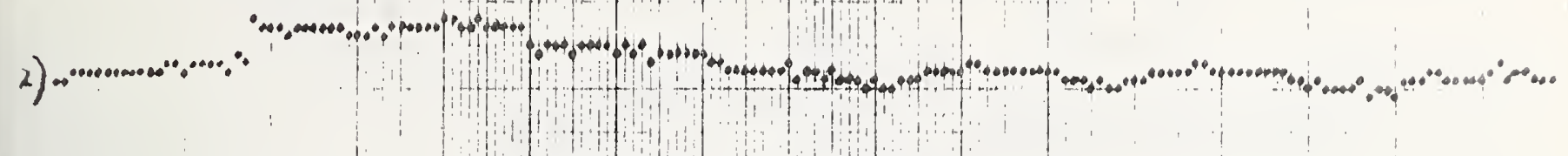

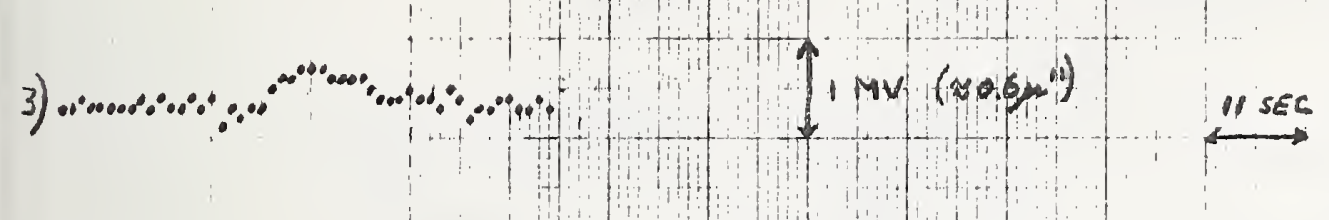

INTEGRATION TIME. Tl. ISECED

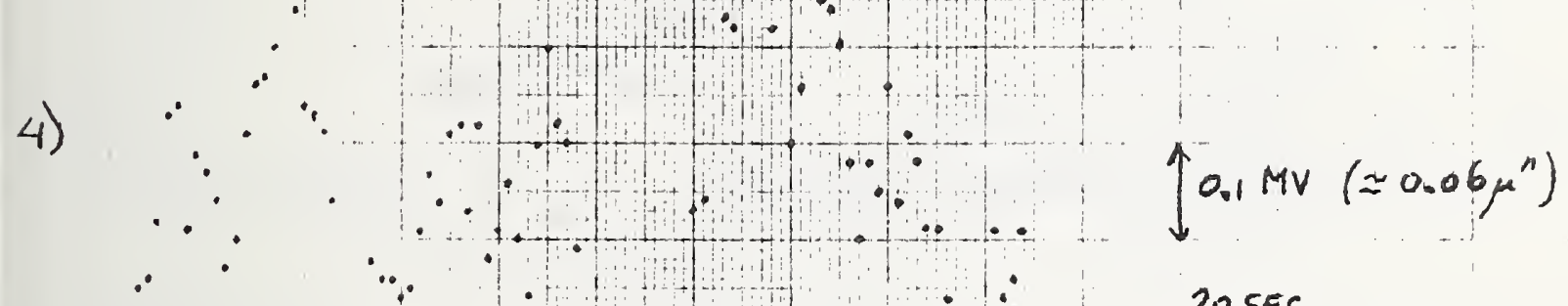

INTECRATION TIME: IO SECONOS

$\stackrel{20 \mathrm{SEC}}{\longleftrightarrow}$

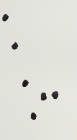

.

5).

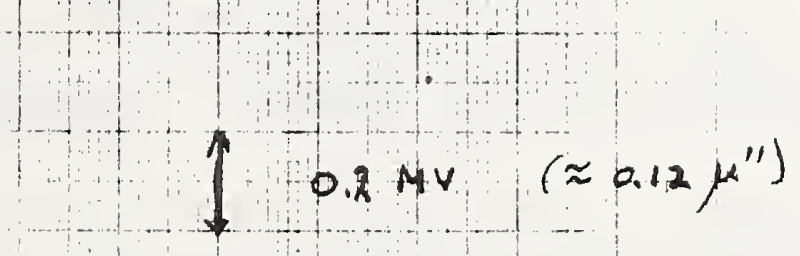

\section{5 sec}

FIG. 13 


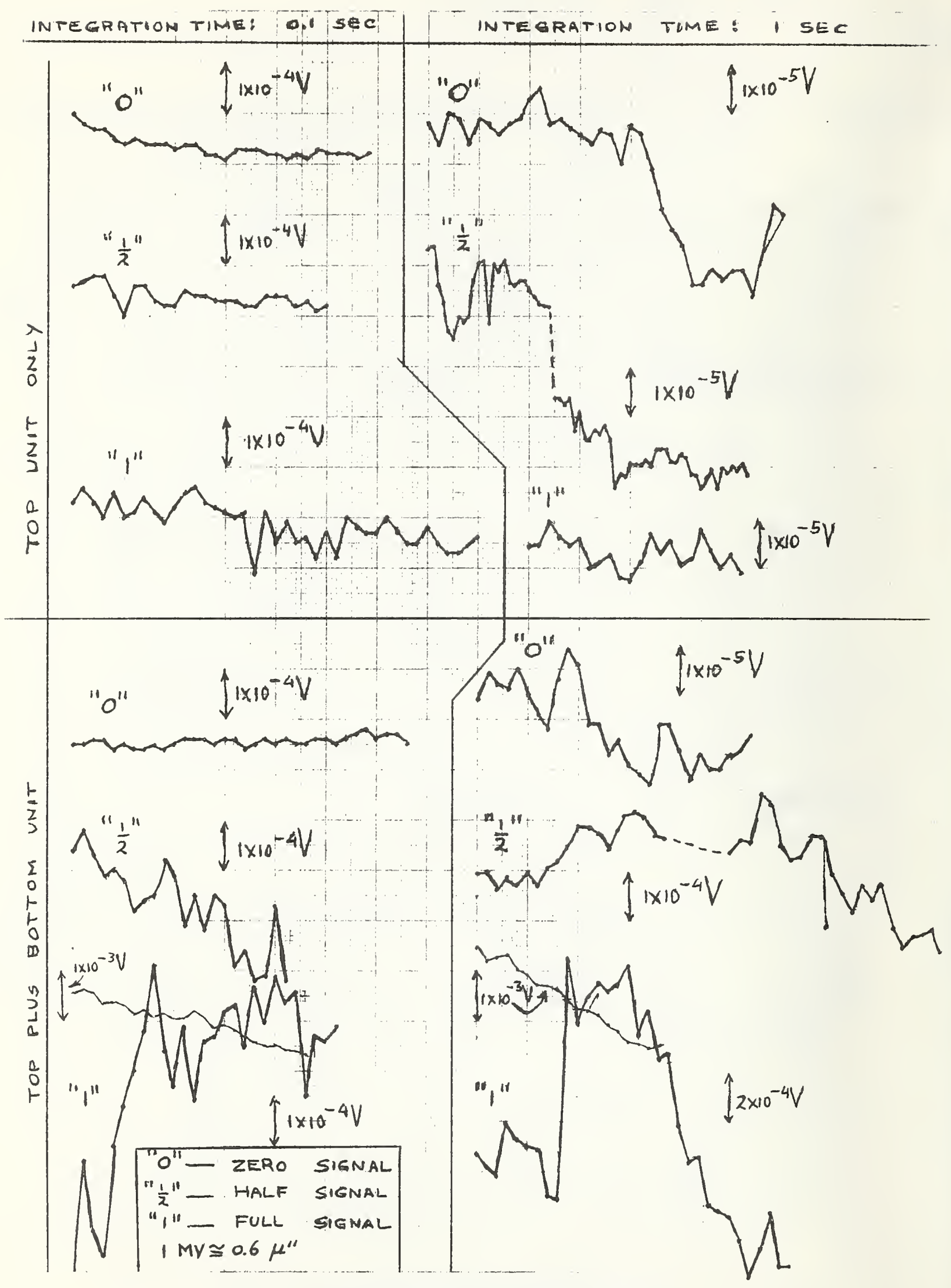

FIG. 14

PROBE NOISE VS SIGNAL STRENGTH 


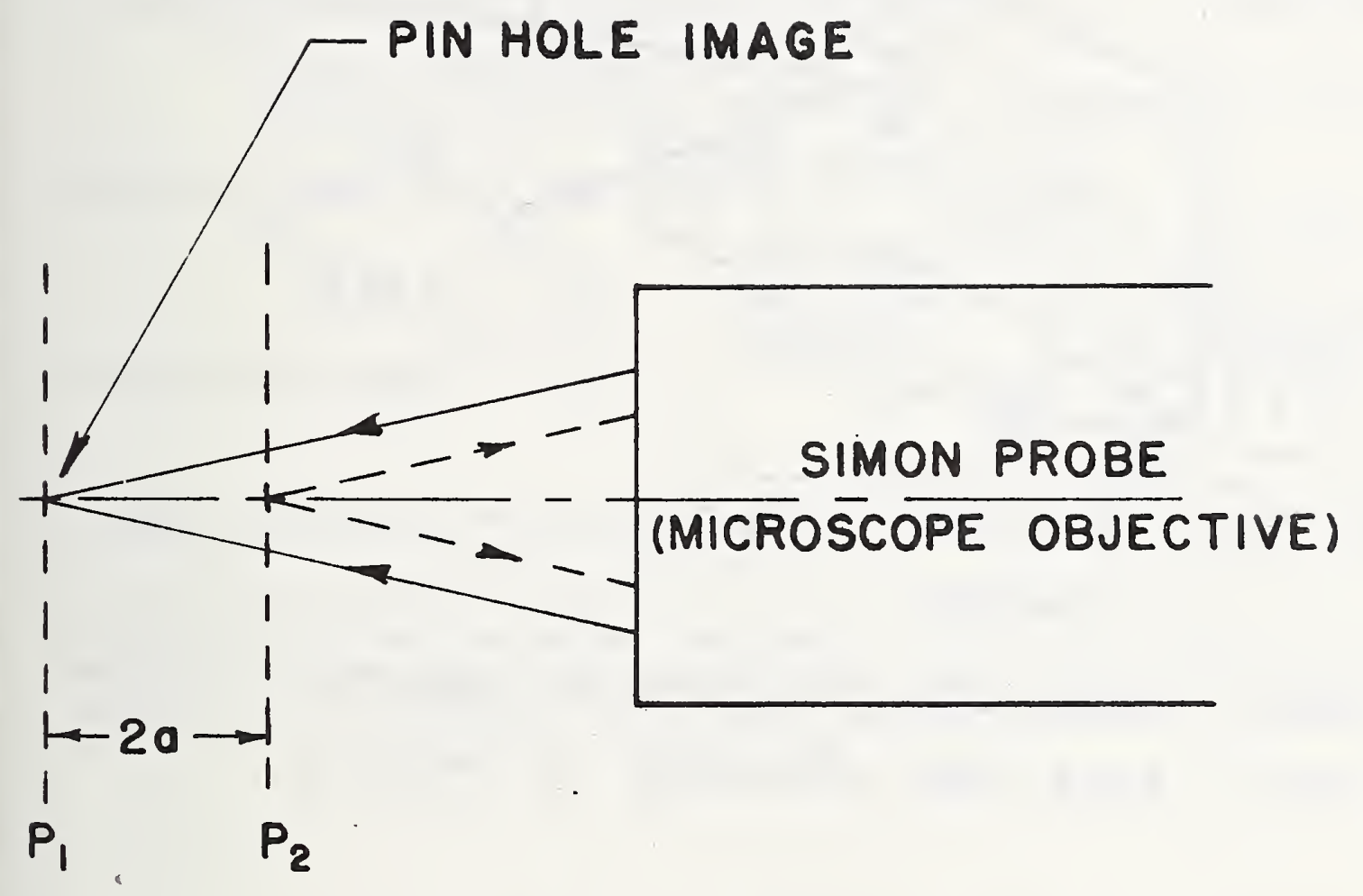

$P_{1}=$ PLANE OF FIELD STOP IMAGE

$P_{2}=$ PLANE, SENSED BY BALANCED SENSOR PAIR

THE SENSOR PAIR WILL BE IN BALANCE, WHEN

A DIFFUSE SURFACE IS LOCATED AT PLANE $P_{2}$, OR A SPECULAR SURFACE LOCATED MIDWAY BETWEEN $P_{1}$ AND $P_{2}$.

\section{PROBE OFFSET ERROR}




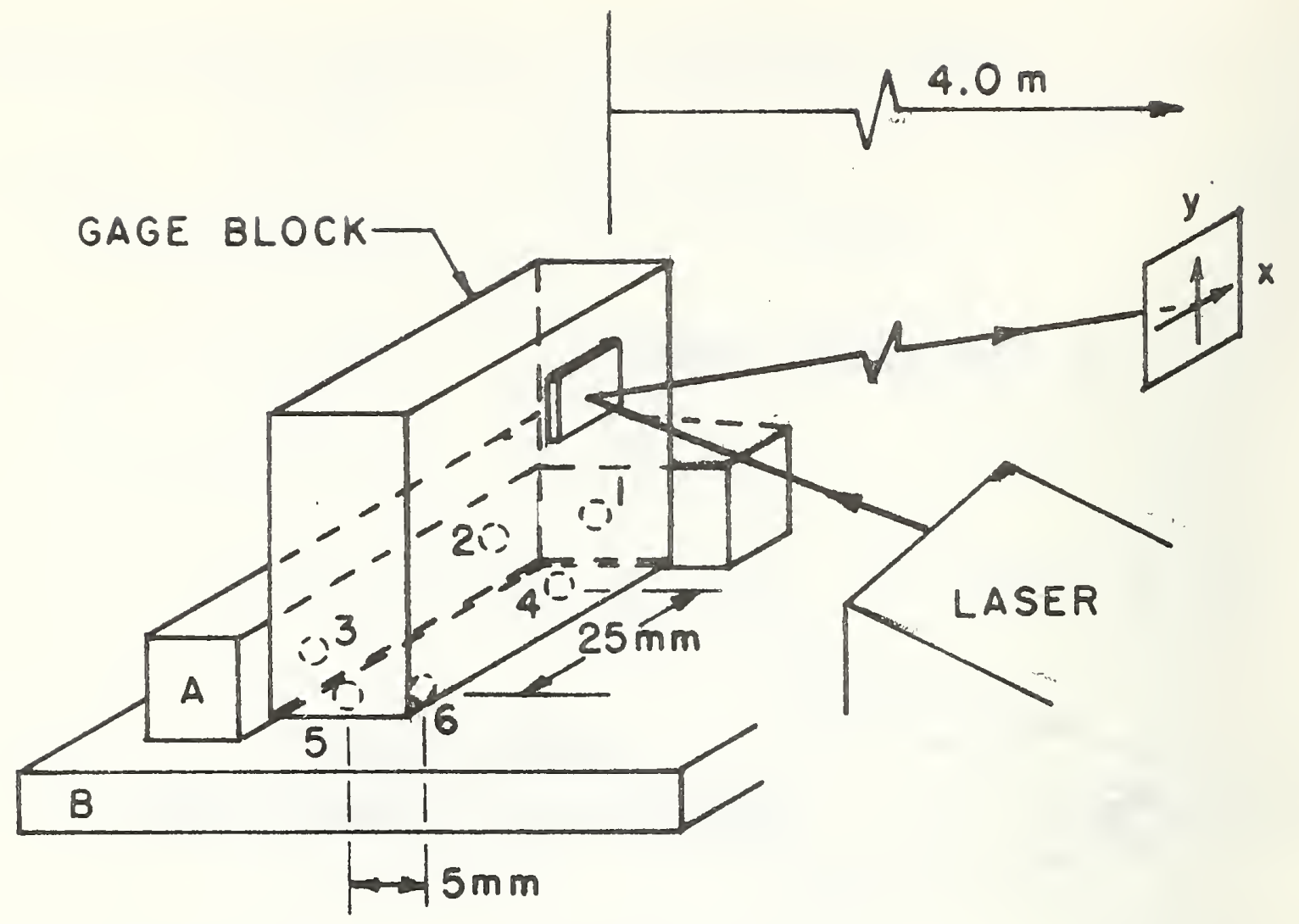

BALLS $1,2,3$ ARE ATTACHED TO PART A BALLS 4,5,6 ARE ATTACHED TO PART 8

REPEATED POSITIONING OF. THE GAGE BLOCK AGAINST ITS STOPS (BALL 1...6) PRODUCES LIGHT DIRECTION VARIATIONS $a_{x}$ AND $a_{y}$

\begin{tabular}{r|rrrrrrrr}
$x(\mathrm{~mm})$ & 21.0 & 21.0 & 21.0 & 21.2 & 20.4 & 21.0 & 21.0 & 20.9 \\
\hline$y(\mathrm{~mm})$ & 8.8 & 8.8 & 8.8 & 8.7 & 8.7 & 8.7 & 8.8 & 8.7
\end{tabular}

$\therefore a_{x} \leq 1 \times 10^{-4} \mathrm{rad}, a_{y} \leq 1 \times 10^{-6} \mathrm{rad}$

SPECIMEN ROTATIONS DUE TO REPOSITIONING

PIGURE 16 
FORM NBS-114A $(1.71)$

\begin{tabular}{|c|c|c|}
\hline $\begin{array}{l}\text { U.S. DEPT. OF COMM. } \\
\text { BIBLIOGRAPHIC DATA } \\
\text { SHEET }\end{array}$ & $\begin{array}{l}\text { T. PUBLICATION OR REPORT NO. } \\
\text { NBSIR } 73-104\end{array}$ & 3. Recipient's Accession No. \\
\hline \multirow{2}{*}{\multicolumn{2}{|c|}{$\begin{array}{l}\text { 4. TITLE AND SUBTITLE } \\
\text { A Non-Contacting Length Comparator with } 10 \text { Nanometer Precision }\end{array}$}} & 5. Publication Date \\
\hline & & 6. Petfocting a aranizarion Code \\
\hline \multicolumn{2}{|c|}{$\begin{array}{l}\text { 7. AUTHOR(S) } \\
\text { A. W. Hartman, F. W. Rosberry and J. Arol Simpson }\end{array}$} & $\begin{array}{l}\text { 8. Performiag Organization } \\
\text { NBSIR } 73-104\end{array}$ \\
\hline \multirow{2}{*}{\multicolumn{2}{|c|}{$\begin{array}{l}\text { 9. PERF ORMING ORGANIZATION NAME AND ADDRESS } \\
\text { NAT IONAL BUREAU OF STAND ARDS } \\
\text { DEPARTMENT OF COMMERCE } \\
\text { WASHINGTON, D.C. } 20234\end{array}$}} & 10. Project/Task/Work Unit No. \\
\hline & & 11. Contract/Grant No. \\
\hline \multicolumn{2}{|c|}{ 12. Sponsoring Organization Name and Address } & $\begin{array}{l}\text { 13. Type of Report \& Period } \\
\text { Covered }\end{array}$ \\
\hline & 14. Sponsoring Agency Code \\
\hline
\end{tabular}

15. SUPPLEMENT ARY NOTES

16. ABSTRACT (A 200-word or less factual summary of most significant information. If document includes a significant bibliography or literature survey, mention it here.)

A non-contacting length comparator utilizing two specially designed photo-electric microscopes has been constructed. Performance tests of this comparator, using lapped and polished steel surfaces demonstrate a resolution of $\sim 1$ nanometer, a precision of $\sim 10$ nanometers, and a linear range in excess of 50 micrometers.

17. KEY WORDS (Alphabetical order, separated by semicolons)

Dimensional metrology; displacement measurement; microscope; noncontact sensing; optical surface probe; surface detection.

\begin{tabular}{|c|c|c|}
\hline $\begin{array}{l}\text { 18. AVAILA BILITY STATEMENT } \\
\square \text { UNLIMIT ED. }\end{array}$ & $\begin{array}{l}\text { 19. SECURITY CLASS } \\
\text { (THIS REPORT) } \\
\text { UNCL ASSIF IED }\end{array}$ & 21. NO. OF PAGES \\
\hline $\begin{array}{l}\text { X FOR OFFICIAL DISTRIBUTION. DO NOT RELEASE } \\
\text { TO NTIS. }\end{array}$ & $\begin{array}{l}\text { 20. SECURITY CLASS } \\
\text { (THIS PAGE) } \\
\text { UNCL ASSIFIED }\end{array}$ & 22. Price \\
\hline
\end{tabular}



